\title{
EVALUATION OF ANTIFUNGAL POTENTIAL OF ALLIUM AMPELOPRASUM AGAINST FUNGAL PHYTOPATHOGENS
}

\author{
SHAHID KHAN, AMANDEEP KAUR, NEETA RAJ SHARMA*
}

Department of Biotechnology, School of Bioengineering and Biosciences, Lovely Professional University, Phagwara, Punjab, India. Email: neeta.raj@lpu.co.in

Received: 22 May 2018, Revised and Accepted: 30 June 2018

\section{ABSTRACT}

Objective: Present study evaluates the antifungal potential of Allium ampeloprasum extracts against two phytopathogens of economic importance, namely Alternaria triticina and Magnaporthe oryzae which are found to be one of the greatest threats to wheat and rice crop worldwide.

Methods: Four different solvents, i.e., water, methanol, acetone, and hexane were used for extract preparation based on the increasing order of polarity. Further, different concentrations of these extracts were used to perform a quantitative assay for measuring the antifungal activity of extracts. Two-way analysis of variance was used to statistically analyze the results through GraphPad Prism v. 7.00.

Results: The best results were shown by water extracts with a maximum inhibition of $99.39 \pm 0.2 \%$ against $A$. triticina and $99.39 \pm 2.2 \%$ against M. oryzae. Water extracts gave minimal inhibitory concentration 90 values at $9.94 \mu \mathrm{g} / \mathrm{mL}$ against $M$. oryzae and at $16.73 \mu \mathrm{g} / \mathrm{mL}$ against $A$. triticina.

Conclusion: Water extracts of $A$. ampeloprasum have relatively higher potential for being used as an antifungal agent as compared to other organic extracts used in this study. Further study on the chemical composition of A. ampeloprasum water extracts can reveal potent anti-phytopathogenic fungal compounds which can be used to develop biofungicides.

Keywords: Allium ampeloprasum, Alternaria, Magnaporthe, Antifungal, Natural compounds.

(C) 2018 The Authors. Published by Innovare Academic Sciences Pvt Ltd. This is an open access article under the CC BY license (http://creativecommons. org/licenses/by/4. 0/) DOI: http://dx.doi.org/10.22159/ajpcr.2018.v11i11.27463

\section{INTRODUCTION}

Fungicides play a significant role in improving crop production and stability, and synthetic fungicides are extensively used worldwide despite their hazards outweigh their benefits. Some fungicides strongly bound to soil instigating soil contamination which may decline mycorrhizal fungi population in soil affecting soil fertility and may also cause groundwater contamination. It is found that the consumption rate of fungicides in India is $13 \%$ and is $21 \%$ at world level [1]. Natural plant products provide limitless prospects for new bioactive compounds both as crude extracts and as pure compounds [2]. Many natural products obtained from plants having biocidal activity are considered as an alternate effective and eco-friendly source against phytopathogens [3]. Moreover, these natural products are usually cheaper than commercial fungicides and are easily accessible to farmers [4]. Allium species is recognized as an important genus of the Alliaceae family and well known for its biocidal properties [5]. Earlier studies have reported that allicin, ajoene, thiosulfinates, and few other phenolic and nitrogen-based bioactive compounds are responsible for the biocidal activity of Allium species [6,7]. Allium ampeloprasum has been considered more beneficial than other Allium species [8] and is known to exhibit strong antifungal activity like A. sativum [9]. A comparative evaluation of the ethanol extracts of A. sativum and A. ampeloprasum showed that A. ampeloprasum possess better antifungal activity and its mild odor makes it preferable for its use as agricultural fungicide [10].

The present study is conducted to examine the antifungal potential of the clove and residue of $A$. ampeloprasum using different organic solvents against two phytopathogens, namely Alternaria triticina and Magnaporthe oryzae. These phytopathogens are threat to crop safety throughout the world; wherein A. triticina is India's second most prevalent wheat pathogen [11] while $M$. oryzae is a rice pathogen which is claimed to be world's most economically harmful phytopathogen [12].

\section{METHODS}

Plant material and chemicals

Fresh sample of $A$. ampeloprasum was obtained from Dosanjh Agricultural Research and Development Farm, Punjab, India. Organic solvents hexane, acetone and methanol were procured from Loba Chemie, and media preparations potato dextrose agar (PDA) and potato dextrose broth (PDB) were procured from HiMedia.

\section{Preparation of extracts}

The A. ampeloprasum sample was thoroughly washed with tap water followed by distilled water to remove any impurities. The cloves were separated from rest of the bulb and allowed to dry in a sterile environment at room temperature; similar treatment was given to the residue. Extraction process as described by Brusotti et al. [13] was used to prepare the extracts using organic solvents in increasing order of their polarity, namely hexane, acetone, methanol, and water with polarity of $0.009,0.355,0.762$, and 1.000 , respectively. Further, the cloves were weighed, crushed in mortar and pestle and then immersed in hexane in $1: 1(\mathrm{w} / \mathrm{v})$ ratio and incubated at room temperature for $48 \mathrm{~h}$ with intermittent stirring to allow maximum diffusion of extracts in solvent. Solvent containing extract was filtered by Whatman filter paper No. 1 and collected in a separate conical flask. The residual was then immersed in acetone for further extraction using a similar procedure and subsequently in other solvents based on the increasing order of their polarity [14]. Likewise, preparation of an extract from A. ampeloprasum residue was also accomplished; A. ampeloprasum residue was comprised the peel, stalk, clove skin, stem, basal plate, and root of the bulb. Solvents containing the extracts were concentrated at $50^{\circ} \mathrm{C}$ to $55^{\circ} \mathrm{C}$ using a vacuum evaporator followed by further drying at room temperature in Petri plate to obtain the powdered extracts. The extracts were then dissolved in their respective solvents to attain a concentration of $1000 \mathrm{mg} / \mathrm{mL}(\mathrm{w} / \mathrm{v})$, sterilized using 0.22 -micron filters and the active constituents from clove and residue of A. ampeloprasum, a 
total of 8 different extracts were obtained which were further subjected to antifungal testing.

\section{Fungal strains and isolation of spores}

The fungal strains used in this study, namely $A$. triticina (Indian Type Culture Collection [ITCC 5496]) and M. oryzae (ITCC 6808) were attained as pure cultures from the ITCC, New Delhi, India. The cultures were revived on PDA at $27^{\circ} \mathrm{C}$ for $5-10$ days using plates and slants; the fungal cultures were renewed after every 15-20 days to keep the culture fresh. Spores were harvested as per the protocol used by Broekart et al. [15], the Petri plates were flooded with PDB, and a sterile spatula was used to detach the spores of the mycelium. The spores were filtered through Whatman filter paper No. 1 and then centrifuged. A spore count of $2^{*} 10^{8}$ was maintained in PDB which was calculated using Neubauer's chamber, and then the fungal spore suspension (spores in PDB) was stored in $50 \%$ glycerol at $-20^{\circ} \mathrm{C}$ for further use.

\section{Testing of antifungal potential}

A 96-well microtiter plate was used to measure the fungal growth inhibition. $200 \mu \mathrm{L}$ A. ampeloprasum extract with a concentration of $200 \mu \mathrm{g} / \mathrm{mL}$ was added to each well of series A and the remaining plate was filled with $100 \mu \mathrm{L}$ of PDB. The serial dilution was done by adding $100 \mu \mathrm{L}$ of $A$. ampeloprasum extract from series A to series B and then from series B to series $C$, and so on until series $\mathrm{G}$. The remaining $100 \mu \mathrm{L}$ from series $\mathrm{G}$ was discarded, and series $\mathrm{H}$ was filled with $100 \mu \mathrm{L}$ pf PDB only and was treated as control. Different plates were used for different extracts and fungi to prevent crosscontamination between the results. The fungal spore suspension was thawed and diluted to make the spore count of $2^{*} 10^{6}$, and $100 \mu \mathrm{L}$ of fungal spore suspension was added to each well of column 1,2 , and 3 . The column 4,5 , and 6 was filled with PDB $(100 \mu \mathrm{L})$ referred as test blank. The final concentration of extracts in each well following the addition of $100 \mu \mathrm{L}$ of fungal spore suspension or $100 \mu \mathrm{L}$ PDB in respective wells, was reduced to half of their initial concentration. Therefore, the final $A$. ampeloprasum extracts concentration ranging from $100 \mu \mathrm{g} / \mathrm{ml}$ to $1.5625 \mu \mathrm{g} / \mathrm{mL}$ from series A to $\mathrm{G}$ was obtained. The wells 1,2 , and 3 in series $\mathrm{H}$ were filled with $100 \mu \mathrm{L}$ of PDB and referred to as negative control, while the well 4, 5, and 6 were referred to as positive control since they contain $100 \mu \mathrm{L}$ of PDB and $100 \mu \mathrm{L}$ of fungal spore suspension. The titer plates were incubated at $27^{\circ} \mathrm{C}$ for $48 \mathrm{~h}$ and to allow sufficient growth and the readings were measured through microplate reader (Bio-Rad at $595 \mathrm{~nm}$ ).

\section{Minimum inhibitory concentration (MIC)}

The MIC was considered as the concentration at which $50 \%$ or $90 \%$ of growth was inhibited, thus $\mathrm{MIC}_{50}$ and $\mathrm{MIC}_{90}$. The percentage of growth inhibition was measured using the equation; $\left[\frac{(\Delta C-\Delta T)}{\Delta C}\right] * 100$, where, $\Delta \mathrm{C}$ is the difference between the average absorbance of positive control and negative control, $\Delta \mathrm{T}$ is the difference between the average absorbance of test and test blank [16].

\section{Statistical analysis}

Percentage growth inhibition was presented as a mean \pm standard deviation, and MIC, i.e., MIC $_{50}$ or MIC $_{90}$ values were determined by the software, Graph v. 4.4.2. The data were statistically analyzed by means of regular two-way analysis of variance at $95 \%$ confidence interval by the software, GraphPad Prism v. 7.00 and Bonferroni post-test was used to compare the percentage growth inhibition of water extracts to other extracts.

\section{RESULTS}

Comparative evaluation of the clove and residue extracts reveals that the antifungal activity of clove extracts increases with an increase in polarity of solvents while the antifungal activity of residue extracts is higher in less polar solvents like hexane. The results of the percentage growth inhibition observed in phytopathogens against different crude extracts of $A$. ampeloprasum clove and residue have been expressed in Tables 1 and 2, respectively. The water extract of $A$. ampeloprasum clove indicated highest antifungal activity among all the tested extracts with maximum fungal growth inhibition of $99.39 \%$ against $A$. triticina and M. oryzae. However, the concentration of extract differed in each case; $A$. triticina showed $99.39 \pm 0.2 \%$ growth inhibition at extract concentration of $100 \mu \mathrm{g} /$ $\mathrm{mL}$ while $M$. oryzae showed $99.39 \pm 2.2 \%$ growth inhibition at extract concentration of $12.25 \mu \mathrm{g} / \mathrm{mL}$. Moreover, the acetone extract of $A$. ampeloprasum clove with maximum growth inhibition of $98.68 \pm 1.1 \%$ at $3.125 \mu \mathrm{g} / \mathrm{mL}$ and the hexane extract of $A$. ampeloprasum residue with maximum growth inhibition of $83.12 \pm 1.2 \%$ at $100 \mu \mathrm{g} / \mathrm{mL}$ against $M$. oryzae were noted as second and third best antifungal extracts, respectively.

Furthermore, some extracts showed poor antifungal activity while others promoted fungal growth.

For instance, among the A. ampeloprasum clove extracts, hexane and methanol extracts showed poor growth inhibition of A. triticina, and acetone extracts slightly promoted its growth at low extract concentrations. Likewise, hexane and methanol extracts of A. ampeloprasum clove also poorly inhibited the growth of M. oryzae, while promoting its growth at certain concentrations as described in Fig. 1a. Conversely, among the A. ampeloprasum residue extracts water, methanol and acetone extracts showed poor antifungal activity against both the fungi as shown in Figs. $2 \mathrm{~b}$ and $2 \mathrm{~b}$. Clove water extract

Table 1: Percentage growth inhibition of $A$. triticina against different crude extracts

\begin{tabular}{|c|c|c|c|c|}
\hline $\begin{array}{l}\text { Concentration of } \\
\text { extracts }(\text { in } \mu \mathrm{g} / \mathrm{mL})\end{array}$ & Hexane & Acetone & Methanol & Water \\
\hline \multicolumn{5}{|l|}{ Clove } \\
\hline 100.00 & $21.63 \pm 0.7^{* * *}$ & $1.16 \pm 0.3^{* * *}$ & $25.69 \pm 1.4^{* * *}$ & $99.39 \pm 0.2$ \\
\hline 50.00 & $29.18 \pm 0.4^{* * *}$ & $3.68 \pm 0.4^{* * *}$ & $19.44 \pm 0.9^{* * *}$ & $98.69 \pm 0.5$ \\
\hline 25.00 & $17.34 \pm 0.8^{* * *}$ & $11.23 \pm 1.3^{* * *}$ & $20.75 \pm 1.1^{* * *}$ & $88.58 \pm 1.6$ \\
\hline 12.50 & $16.08 \pm 0.1^{* * *}$ & $-3.22 \pm 0.4^{* * *}$ & $25.59 \pm 1.5^{* * *}$ & $83.08 \pm 0.8$ \\
\hline 6.25 & $3.26 \pm 0.4^{* * *}$ & $-10.49 \pm 1.5^{* * *}$ & $23.59 \pm 2.3^{* * *}$ & $83.50 \pm 0.8$ \\
\hline 1.5625 & $3.49 \pm 1.9^{* * *}$ & $-7.55 \pm 1.5^{* * *}$ & $20.23 \pm 3.7^{* * *}$ & $83.03 \pm 0.4$ \\
\hline \multicolumn{5}{|l|}{ Residue } \\
\hline 100.00 & $34.27 \pm 0.4^{* * *}$ & $13.24 \pm 1.8^{* * *}$ & $19.07 \pm 1.6^{* * *}$ & $22.28 \pm 0.9^{* * *}$ \\
\hline 50.00 & $29.56 \pm 0.5^{* * *}$ & $14.55 \pm 0.6^{* * *}$ & $13.71 \pm 1.0^{* * *}$ & $20.75 \pm 0.5^{* * *}$ \\
\hline 25.00 & $30.91 \pm 0.2^{* * *}$ & $17.20 \pm 0.5^{* * *}$ & $31.70 \pm 0.3^{* * *}$ & $19.53 \pm 1.3^{* * *}$ \\
\hline 12.50 & $25.64 \pm 0.8^{* * *}$ & $8.95 \pm 0.3^{* * *}$ & $31.42 \pm 1.8^{* * *}$ & $16.74 \pm 1.5^{* * *}$ \\
\hline 6.25 & $23.45 \pm 0.2^{* * *}$ & $8.58 \pm 0.7^{* * *}$ & $30.26 \pm 0.1^{* * *}$ & $-18.83 \pm 1.5^{* * *}$ \\
\hline 3.125 & $19.77 \pm 0.3^{* * *}$ & $0.65 \pm 0.4^{* * *}$ & $30.12 \pm 0.9 * * *$ & $-15.71 \pm 1.4^{* * *}$ \\
\hline
\end{tabular}


Table 2: Percentage growth inhibition of M. oryzae against different crude extracts

\begin{tabular}{|c|c|c|c|c|}
\hline $\begin{array}{l}\text { Concentration of } \\
\text { extracts (in } \mu \mathrm{g} / \mathrm{mL} \text { ) }\end{array}$ & Hexane & Acetone & Methanol & Water \\
\hline \multicolumn{5}{|l|}{ Clove } \\
\hline 100.00 & $-37.86 \pm 1.3^{* * *}$ & $61.23 \pm 0.9 * * *$ & $-3.25 \pm 1.0^{* * *}$ & $50.58 \pm 5.5$ \\
\hline 50.00 & $-37.21 \pm 1.0^{* * *}$ & $76.63 \pm 0.9^{* * *}$ & $-22.13 \pm 1.1^{* * *}$ & $36.08 \pm 2.3$ \\
\hline 25.00 & $-56.83 \pm 3.2^{* * *}$ & $86.29 \pm 1.2 \mathrm{~ns}$ & $-20.39 \pm 1.4^{* * *}$ & $82.14 \pm 1.5$ \\
\hline 12.50 & $10.78 \pm 1.0^{* * *}$ & $92.39 \pm 1.4^{* * *}$ & $1.95 \pm 2.3^{* * *}$ & $99.39 \pm 2.2$ \\
\hline 6.25 & $13.08 \pm 1.5^{* * *}$ & $88.02 \pm 1.4^{* * *}$ & $-1.63 \pm 1.2^{* * *}$ & $76.47 \pm 1.9$ \\
\hline 1.5625 & $55.60 \pm 2.2^{* * *}$ & $79.64 \pm 1.1^{* *}$ & $-33.19 \pm 0.9^{* * *}$ & $86.05 \pm 0.7$ \\
\hline \multicolumn{5}{|l|}{ Residue } \\
\hline 100.00 & $83.12 \pm 1.2^{* * *}$ & $15.49 \pm 0.3^{* * *}$ & $10.41 \pm 0.9^{* * *}$ & $48.37 \pm 2.6 n s$ \\
\hline 50.00 & $78.02 \pm 1.3^{* * *}$ & $29.34 \pm 1.7^{* * *}$ & $-6.18 \pm 3.4^{* * *}$ & $40.14 \pm 6.0 \mathrm{~ns}$ \\
\hline 25.00 & $45.62 \pm 1.3^{* * *}$ & $25.97 \pm 1.3^{* * *}$ & $-34.38 \pm 0.6^{* * *}$ & $26.69 \pm 0.5^{* * *}$ \\
\hline 12.50 & $40.45 \pm 1.3^{* * *}$ & $15.03 \pm 3.9^{* * *}$ & $-21.37 \pm 1.4^{* * *}$ & $8.63 \pm 4.7^{* * *}$ \\
\hline 6.25 & $27.87 \pm 1.3^{* * *}$ & $7.29 \pm 1.1^{* * *}$ & $-20.82 \pm 1.0^{* * *}$ & $34.87 \pm 2.4^{* * *}$ \\
\hline 3.125 & $21.26 \pm 1.6^{* * *}$ & $-3.05 \pm 1.0^{* * *}$ & $-74.40 \pm 1.1^{* * *}$ & $1.15 \pm 1.0^{* * *}$ \\
\hline
\end{tabular}

***Indicates $(\mathrm{p}<0.001),{ }^{* *}$ indicates $(\mathrm{p}<0.01)$, ns: Indicates $(\mathrm{p}>0.05)$. M. oryzae: Magnaporthe oryzae

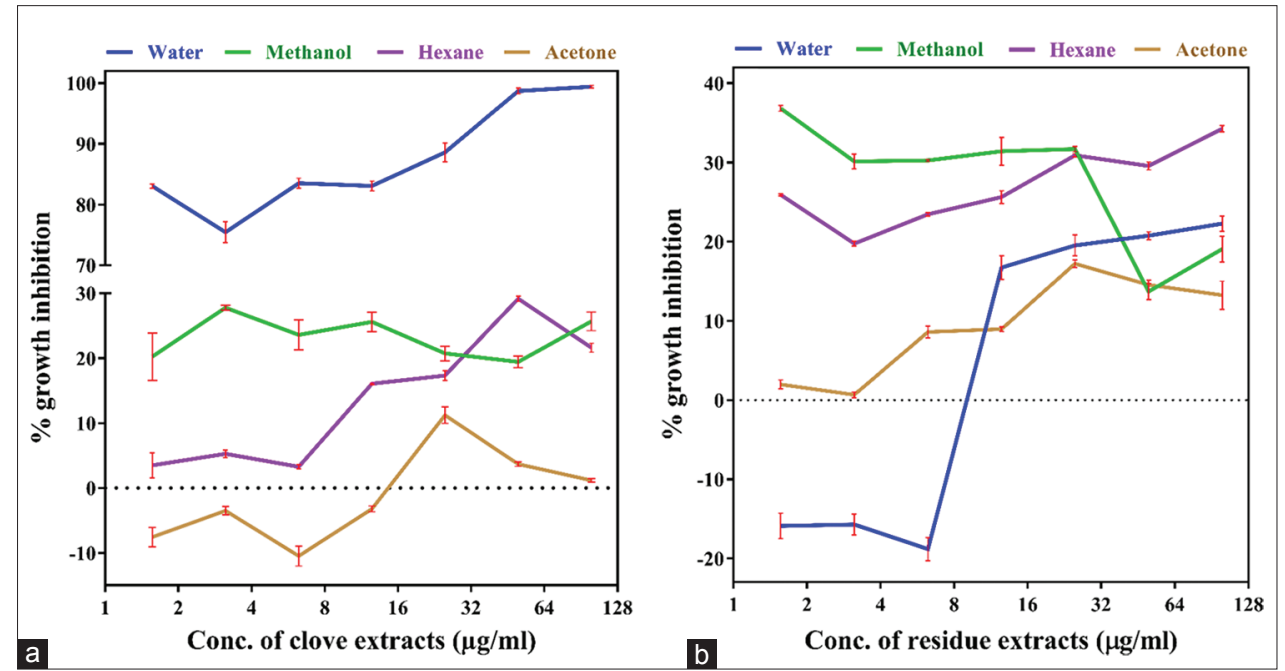

Fig. 1: Effect of the Allium ampeloprasum crude extracts on the growth of Alternaria triticina (a) clove extracts (b) residue extracts
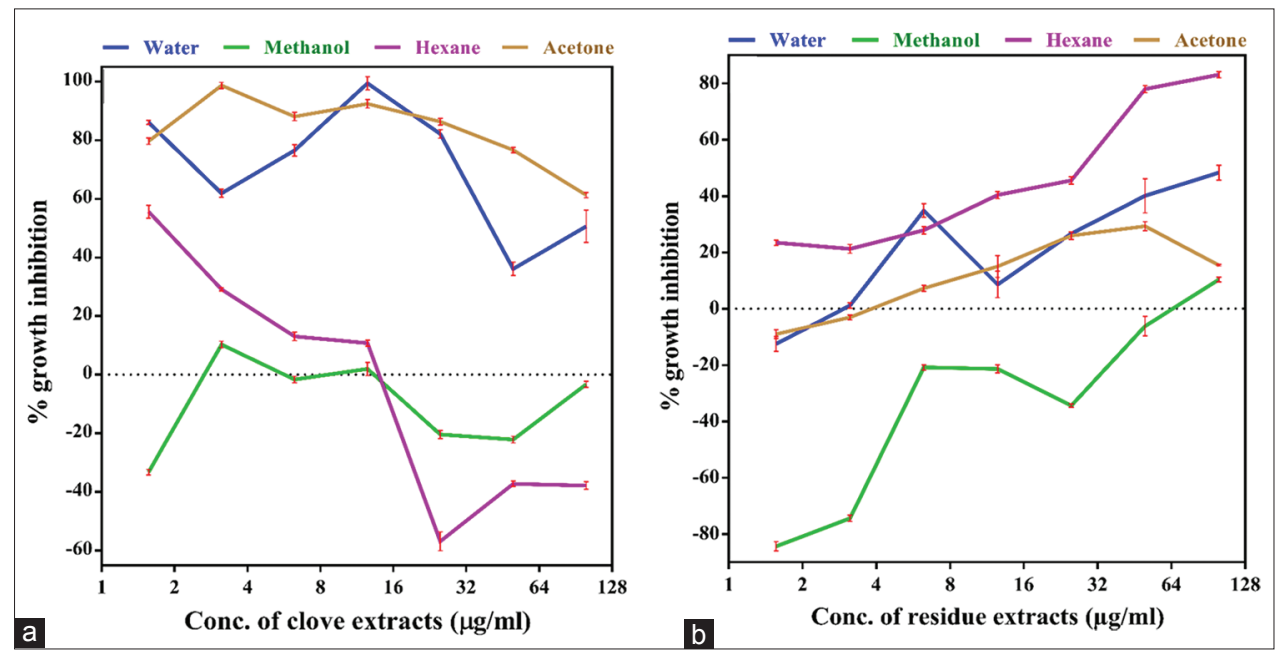

Fig. 2: Effect of the Allium ampeloprasum crude organic extracts on the growth of Magnaporthe oryzae (a) clove extracts (b) residue extracts

promoted the growth of A. triticina at lower concentrations, as shown in Fig. 2a. While acetone, methanol and water clove extracts promoted the growth of M. oryzae at various concentrations, the details are discussed in Table 2.
A total of 56 different combinations of extracts were tested against each fungus, on considering the extract from two sources, four organic solvents, and seven different concentrations as individual extracts. Extracts showing more than $25 \%$ growth inhibition were considered 
significant; according to which $37.50 \%$ extracts showed significant growth inhibition against $A$. triticina, i.e., 21 of 56 extracts and $48.21 \%$ showed significant growth inhibition against $M$. oryzae, i.e., 27 of 56 extracts. On the contrary, the extracts showing negative growth inhibition were basically promoting fungal growth; the analysis of results shows that $12.50 \%, 7$ extracts among the total of 56 extracts promoted growth of $A$. triticina while $30.35 \%$ extracts, i.e., 17 of 56 extracts promoted growth of $M$. oryzae.

MIC, namely $\mathrm{MIC}_{50}$ and $\mathrm{MIC}_{90}$ values were calculated to evaluate the antifungal potential of extracts, and the details are displayed in Fig. 3. In case of the water extract of $A$. ampeloprasum clove, $\mathrm{MIC}_{50}$ value was obtained at $42.24 \mu \mathrm{g} / \mathrm{mL}$ concentration, and $\mathrm{MIC}_{90}$ value was obtained at $9.94 \mu \mathrm{g} / \mathrm{mL}$ concentration against $M$. oryzae, whereas only $\mathrm{MIC}_{90}$ value was observed at $16.73 \mu \mathrm{g} / \mathrm{mL}$ concentration against A. triticina. In addition, the A. ampeloprasum clove extracts showed the $\mathrm{MIC}_{90}$ value of $2.41 \mu \mathrm{g} / \mathrm{mL}$ and $\mathrm{MIC}_{50}$ value of $1.89 \mu \mathrm{g} / \mathrm{mL}$ against $\mathrm{M}$. oryzae for acetone and hexane extract, respectively. Whereas, among the $A$. ampeloprasum residue extracts $\mathrm{MIC}_{50}$ value at $28.32 \mu \mathrm{g} / \mathrm{mL}$ was shown by hexane extract against $M$. oryzae. Based on this information, it could be established that the water extract of $A$. ampeloprasum clove has the best antifungal potential for further use as an antifungal agent. Therefore, the water extracts were used as standards for statistical analysis of all extracts and the results shows that all the extracts. Results indicate that all extracts were significantly different against $A$. triticina with $\mathrm{p}<0.001$, while in the case of $M$. oryzae all but four extracts were significantly different with $\mathrm{p}<0.001$

\section{DISCUSSION}

Allium species are known to inhibit a wide range of pathogenic fungi mostly due to the presence of allicin, ajoene, and organosulfur compounds [17-19]. Analysis of 29 different plant extracts against Alternaria species shows that $31 \%$, nine plant extracts exhibit significant antifungal activity where Cynara scolymus, Lippia alba, Salvia sclarea, and Salvia officinalis showed approximately $98 \%$ growth inhibition of Alternaria species which is equivalent to the growth inhibition shown by commercial fungicides [16]. A study conducted on pathogen infested wheat suggests that coating wheat seedlings with Allium juice before sowing leads to better growth and advocates fungicidal potential of $A$. ampeloprasum products [20].

Antifungal analysis of $A$. sativum extracts against different fungal pathogens of coffee tree shows that the A. ampeloprasum extracts can inhibit mycelial growth by $100 \%$ as well as also effectively preventing the germination of spores [4]. It is found that the mechanism of action, of $A$. ampeloprasum as an antifungal agent, is due to the competitive inhibition of sulfhydryl-containing enzymes by allicin and the inhibition of lipid biosynthesis leading to cell wall damage, as seen in the case of Candida albicans [9,21]. In accordance to our study, a former study also concludes that elephant $A$. ampeloprasum clove has better activity than A. ampeloprasum skin and seed [9]. The efficacy of cinnamic acid derivatives isolated from A. ampeloprasum against four fungal pathogens and cheap traceability makes them a potential fungicide [6]. Three steroidal saponins and aginoside isolated from A. ampeloprasum were found to exhibit antifungal activity against Mortierella ramanniana [22]. An in vitro study on biologically active saponin isolated from seeds $A$. ampeloprasum reveals that butanolic extracts were found to completely inhibit the growth of Alternaria alternata at $200 \mu \mathrm{g} / \mathrm{mL}$ concentration and a concentration of $400 \mu \mathrm{g} /$ $\mathrm{mL}$, the butanolic extracts completely inhibits the growth of Fusarium roseum, Colletotrichium dematium, Curvularia lunata, and Aspergillus fumigatus [23]. A recent study on ethanolic extracts obtained from Allium species supports that $A$. ampeloprasum possesses antifungal potentially against $A$. triticina and $M$. oryzae [10].

\section{CONCLUSION}

All the crude extracts of $A$. ampeloprasum clove and A. ampeloprasum residue showed erratic antifungal activity irrespective of extract's concentration. Clove extract showed much better antifungal

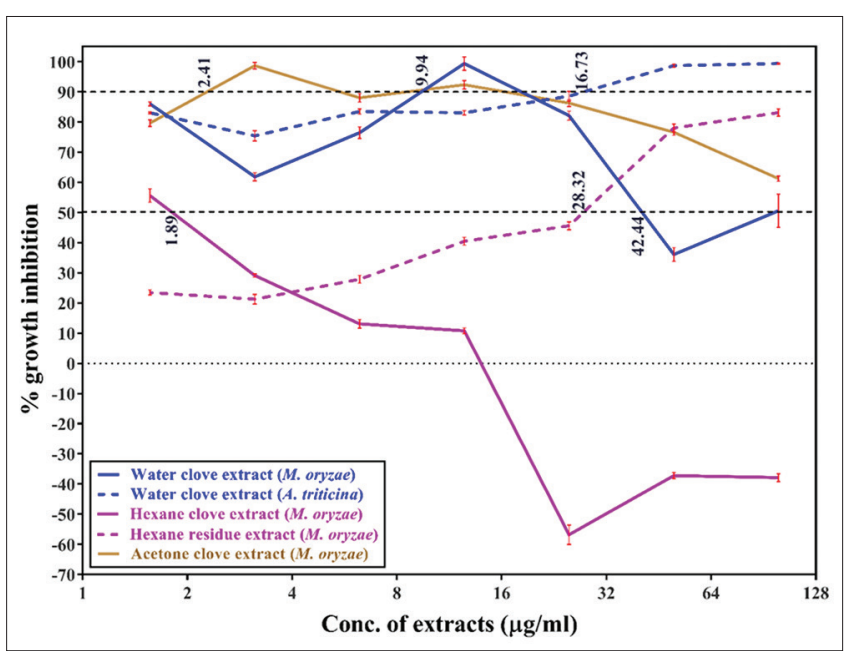

Fig. 3: Minimum inhibitory concentration ${ }_{50}\left(\mathrm{MIC}_{50}\right)$ and MIC $_{90}$ values of the organic extracts in different solvents

activity than residue extracts. Acetone extracts showed the weakest activity against $A$. triticina, and methanol extract showed the weakest activity against $M$. oryzae. It could be concluded from this study that, water extract of $A$. ampeloprasum can induce high antifungal activity against one of the most harmful phytopathogens of economic importance and hence, could be used as potential biofungicide. Further investigation to isolate pure compounds from water extract having best antifungal activity could be conducted to formulate an effective and economical biofungicide.

\section{ACKNOWLEDGMENT}

Authors are obliged to the management of Lovely Professional University for providing laboratory support. Authors also express regard to Dosanjh Agricultural Research and Development Farm, Punjab, for providing A. ampeloprasum samples for our research.

\section{AUTHORS' CONTRIBUTIONS}

Dr. Sharma devised the conceptual idea which was further carried out in the laboratory by Er. S. Khan followed by developing draft Manuscript. Dr. Sharma supervised the technical details and finalized the manuscript. Er. A. Kaur procured the plant material and maintained the stock simultaneously prepared the extracts.

\section{CONFLICTS OF INTEREST}

The authors declare that they have no conflicts of interest in the publication.

\section{REFERENCES}

1. Aktar MW, Sengupta D, Chowdhury A. Impact of pesticides use in agriculture: Their benefits and hazards. Interdiscip Toxicol 2009;2:1-12.

2. Sasidharan S, Chen Y, Saravanan D, Sundram KM, Latha LY. Extraction, isolation and characterization of bioactive compounds from plants extracts. Afr J Tradit Complement Altern Med 2011;8:1-10.

3. Borrego S, Valdes O, Vivar I, Lavin P, Guiamet P, Battistoni P, et al. Essential oils of plants as biocides against microorganisms isolated from Cuban argentine documentary heritage. ISRN Microbiol 2012; ArticleID 826786:7.

4. Silva JL, Souza PE, Monteiro FP, Freitas MLO, Silva JMB, Belan LL. Antifungal activity using medicinal plant extracts against pathogens of coffee tree. Revista Brasileira de Plantas Med 2014;16:539-44.

5. Mnayer D, Fabiano-Tixier AS, Petitcolas E, Hamieh T, Nehme N, Ferrant $\mathrm{C}$, et al. Chemical composition, antibacterial and antioxidant activities of six essentials oils from the alliaceae family. Molecules 2014;19:20034-53.

6. Sadeghi M, Zolfaghari B, Senatore M, Lanzotti V. Antifungal cinnamic acid derivatives from Persian leek (Allium ampeloprasum Subsp. 
Persicum). Phytochem Lett 2013;6:360-3.

7. Yoshida S, Kasuga S, Hayashi N, Ushiroguchi T, Matsuura H, Nakagawa S. Antifungal activity of ajoene derived from A. ampeloprasum. Appl Environ Microbiol 1987;53:615-7.

8. Dey P, Khaled KL. An extensive review on Allium ampeloprasum a magical herb. Int J Sci Res 2013;4:371-7.

9. Hughes BG and Lawson LD. Antimicrobial effects of Allium sativum L. (A. ampeloprasum), Allium ampeloprasum L. (Elephant A. ampeloprasum), and Alliumcepa L. (Onion), A. ampeloprasum compounds and commercial A. ampeloprasum supplement products. Phytother Res 1991;5:154-8.

10. Khan S, Sharma NR. Antifungal potential of ethanol extracts of Allium sativum and Allium ampeloprasum. Asian J Pharm Clin Res 2017;10:207-10.

11. Singh RN, Singh AK, Singh SP, Singh BN. Prevalence and distribution of foliar blight pathogens attacking wheat in India. Indian Phytopathol 2001;54:175-8.

12. Dean R, VanKan JA, Pretorius ZA, Hammond-Kosack KE, Di Pietro A, Spanu PD, et al. The top 10 fungal pathogens in molecular plant pathology. Molecular Plant Pathol 2012;13:414-30.

13. Brusotti G, Cesari I, Dentamaro A, Caccialanza G, Massolini G. Isolation and characterization of bioactive compounds from plant resources: The role of analysis in the ethnopharmacological approach. J Pharm BiomedAnal 2014;87:218-28

14. Reichdart C, Welton T. Solvents and solvent effects in organic chemistry. $4^{\text {th }}$ ed. Weinheim: Wiley-VCH Verlag GmbH \& Co.; 2011.
15. Broekart WF, Terras RF, Cammune BP, Vanderleyden J. An automated quantitative assay for fungal growth inhibition. FEMS Microbiol Lett 1990;69:55-60.

16. Dellavalle PD, Cabrera A, Alem D, Larranga P, Ferriera F, Rizza MD. Antifungal activity of medicinal plant extracts against phytopathogenic fungus Alternaria spp. Chilean J Agric Res 2011;71:231-9.

17. Lanzotti V, Bonanomi G, Scala F. What makes Allium species effective against pathogenicmicrobes? Phytochem Rev 2013;12:751-72.

18. Mishra N, Behal KK, Antimicrobial activity of some spices against selected microbes. Int J Pharm Pharm Sci 2010;2:187-96.

19. Sharanappa R, Vidyasagar GM. Anti-Candida activity of medicinal plants. A review. Int J Pharm Pharm Sci 2013;5:9-16.

20. Perelló A, Gruhlke M, Slusarenko AJ. Effect of A. ampeloprasum extract on seed germination, seedling health, and vigour of pathogeninfested wheat. J Plant Prot Res 2013;53:317-23.

21. Adetumbi M, Javor GT, Lau BH. Allium sativum (A. ampeloprasum) inhibits lipid synthesis by Candida albicans. Antimicrob. Antimicrobial Agents Chemother 1986;30:499-501.

22. Sata N, Matsunaga S, Fusetani N, Nishikawa H, Takamura S, Saito T. New antifungal and cytotoxic steroidal saponins from the bulbs of an elephant $A$. ampeloprasum mutant. Biosci Biotechnol Biochem 1998;62:1904-11.

23. Acharya C, Choubey A, Acharya M. Biologically active saponin from seeds of Allium ampeloprasum. Chem Mater Res 2013;3:2224-3224. 